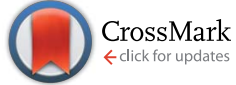

Cite this: J. Mater. Chem. A, 2016, 4, 4718

Received 31st December 2015 Accepted 2nd March 2016

DOI: $10.1039 / c 5 t a 10781 d$

\section{Realization of high performance flexible wire supercapacitors based on 3-dimensional $\mathrm{NiCO}_{2} \mathrm{O}_{4} /$ Ni fibers $\dagger$}

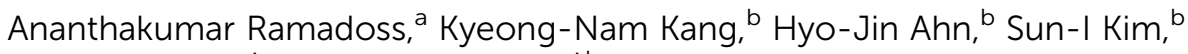 \\ Seung-Tak Ryu*a and Ji-Hyun Jang ${ }^{\star b}$
}

www.rsc.org/MaterialsA

The rapidly developing electronics industry is producing miniaturized electronic devices with flexible, portable and wearable characteristics, requiring high-performance miniature energy storage devices with flexible and light weight properties. Herein, we have successfully fabricated highly porous, binder free three-dimensional flower-like $\mathrm{NiCO}_{2} \mathrm{O}_{4} / \mathrm{Ni}$ nanostructures on $\mathrm{Ni}$-wire as a fiber electrode for highperformance flexible fiber supercapacitors. Such a unique structure exhibited remarkable electrochemical performance with high capacitance $\left(29.7 \mathrm{~F} \mathrm{~cm}^{-3}\right.$ at $2.5 \mathrm{~mA}$ ), excellent rate capability ( $97.5 \%$ retention at $20 \mathrm{~mA})$, and super cycling stability $(80 \%$ retention, even after 5000 cycles). The remarkable electrochemical performance is attributed to the large active area in the 3D porous architecture and direct contact between the active materials and 3D-Ni current collectors, which facilitate easy ionic/electronic transport. The symmetric fiber supercapacitor showed a gravimetric energy density of $2.18 \mathrm{~W} \mathrm{~h} \mathrm{~kg} \mathrm{~W}^{-1}$ $\left(0.21 \mathrm{~mW} \mathrm{~h} \mathrm{~cm}^{-3}\right)$ and a power density of $\left.21.6 \mathrm{~W} \mathrm{~kg}^{-1}(2.1 \mathrm{~mW} \mathrm{~cm})^{-3}\right)$ with good flexibility and cycling performance, signifying potential applications in high-performance flexible energy storage devices. Further, performance in a self-powered system was demonstrated by charging these wire type $\mathrm{NiCO}_{2} \mathrm{O}_{4} / \mathrm{Ni}$ supercapacitors by serially wound DSSCs to drive commercial LEDs. These results suggest that the fabricated device has excellent potential as a power source for flexible, portable and wearable applications as well as self-powered systems.

\footnotetext{
${ }^{a}$ Mixed Signal Integrated Circuit Lab, School of Electrical Engineering, Korea Advanced Institute of Science and Technology, Daejeon 305-701, Republic of Korea. E-mail: stryu@kaist.ac.kr; Fax: +82-52-217-3008; Tel: +82-52-217-2922

${ }^{b}$ School of Energy and Chemical Engineering, Low Dimensional Carbon Materials Center, Ulsan National Institute of Science and Technology, Ulsan 689-798, Republic of Korea.E-mail: clau@unist.ac.kr

$\dagger$ Electronic supplementary information (ESI) available: Experimental details of the flexible solid-state fiber supercapacitor. XRD, Raman, XPS, FE-SEM and EDS analysis data of $3 \mathrm{D}$ porous flower-like $\mathrm{Ni} / \mathrm{NiCo}_{2} \mathrm{O}_{4}$ nanostructures. Electrochemical performance of 3D-NCO/Ni-1, 3D-NCO/Ni-2, and 3D-NCO/Ni-3 electrodes. Gravimetric and areal capacitances of the fabricated electrodes as a function of scan rate and current for the three electrode system. Nyquist plots of Ni-wire, 3D-Ni and 3D-NiCo $\mathrm{O}_{4} / \mathrm{Ni}$ electrodes. Schematic diagram and data of the DSSCs. Leakage current and self-discharge of the serially connected fiber supercapacitors. See DOI: 10.1039/c5ta10781d
}

\section{Introduction}

Modern society is continually searching for the next advanced versions of multifunctional electronic devices, and particularly, for improvements that produce smaller size, lighter weight, flexible, wearable, and self-powered devices. At the same time, these recent technological trends have stimulated demand for the development of a suitable independent power supply that can be used for portable electronic devices, wireless networks and other self-powered micro/nano-device systems.$^{1-3}$ Lately, flexible supercapacitors, a new kind of flexible energy storage device, have received much attention for next-generation energy storage due to their remarkable features, including their light weight, stability, portability, flexibility, safety, and eco-friendliness. ${ }^{4-10}$

Flexible supercapacitors on metal sheets, carbon cloth, papers, textiles and plastic substrates are widely employed as wearable and portable energy storage devices. ${ }^{11-13}$ In order to further reduce their size and increase compatibility, fiber and cable-type flexible supercapacitors have been developed. Recently, Wang et al. ${ }^{14}$ fabricated a coaxial-type fiber supercapacitor based on $\mathrm{NiCo}_{2} \mathrm{O}_{4}$ nanosheets, which reached a volumetric capacitance of $10.3 \mathrm{~F} \mathrm{~cm}^{-3}$ at $0.08 \mathrm{~mA}$. Similarly, $\mathrm{Gu}$ et al. ${ }^{15}$ and Wu et al. ${ }^{16}$ prepared $\mathrm{CuCo}_{2} \mathrm{O}_{4}$ and $\mathrm{ZnCo}_{2} \mathrm{O}_{4}$ based fiber supercapacitors with capacitances of $11.09 \mathrm{~F} \mathrm{~g}^{-1}$ at $2 \mathrm{~mA}$ and $10.9 \mathrm{~F} \mathrm{~g}^{-1}$ at $30 \mathrm{mV} \mathrm{s}^{-1}$, respectively. Liu et al. ${ }^{17}$ reported a planar integrated $\mathrm{ZnCo}_{2} \mathrm{O}_{4}$ nano-arrays/carbon fiber supercapacitor with the capacitance of $0.6 \mathrm{~F} \mathrm{~g}^{-1}$ at $1 \mathrm{~A} \mathrm{~g}^{-1}$. Carbon/ $\mathrm{MnO}_{2}(\mathrm{C} / \mathrm{M})$ core-shell fiber ${ }^{18}$ and graphene/carbon nanotube (CNT) composite fiber supercapacitors ${ }^{19}$ showed a specific capacitance of $2.5 \mathrm{~F} \mathrm{~cm}^{-3}$ and $4.97 \mathrm{mF} \mathrm{cm}^{-2}$, respectively.

However, while recent research efforts have been made to fabricate flexible fiber supercapacitors via various methods, further investigation still needs to be conducted to improve their performance for practical applications. For example, most reported fiber supercapacitors have been based on metal wire current collectors with smooth surfaces, low surface area, and low porosity, which produces large contact resistance between the active materials and the current collector substrate, which 
leads to low performance. Hence, the main focus should be on reducing the internal resistance for faster charge transport, increasing the active surface area to permit easy access for electrolyte ions, and enhancing cyclic stability by controlling the morphology of microstructures.

Herein, we introduce a three-dimensional (3D) current collector, a 3D porous nickel (3D-Ni) architecture on a Ni-wire substrate, for constructing next generation flexible fiber supercapacitors. The 3D-Ni was prepared by electrodeposition in the presence of hydrogen bubble templates, and possesses highly porous dendritic walls with many electroactive sites connected by highly conductive networks and short diffusion path lengths. This allows for easy transport of ions/electrons, leading to more efficient contact between the electrolyte ions and electroactive sites for faradaic energy storage, and thus results in high charge/discharge rates even at high-current densities. In addition to good flexibility, this binder and conductive additive-free 3D-Ni/Ni-wire allows for high mechanical strength, low cost, and ease of fabrication.

$\mathrm{NiCo}_{2} \mathrm{O}_{4}$ electroactive materials were grown onto a $3 \mathrm{D}-\mathrm{Ni} / \mathrm{Ni}-$ wire current collector using the electrodeposition method, and the combination provided better electronic conductivity and higher electrochemical activity than those of nickel oxide and cobalt oxide. The as-prepared three-dimensional porous flowerlike $\mathrm{NiCo}_{2} \mathrm{O}_{4}$ on 3D-Ni/Ni-wire $\left(3 \mathrm{D}-\mathrm{NiCO}_{2} \mathrm{O}_{4} / \mathrm{Ni}\right)$ exhibited an outstanding volumetric capacitance of $29.7 \mathrm{~F} \mathrm{~cm}^{-3}$ with good rate capability ( $97.5 \%$ at $20 \mathrm{~mA})$. Further, the planar-integrated fiber supercapacitor exhibited excellent cycling stability $(100 \%$ retention even after 5000 cycles) and flexibility with an energy density of $2.18 \mathrm{~W} \mathrm{~h} \mathrm{~kg}{ }^{-1}$ and a power density of $21.6 \mathrm{~W} \mathrm{~kg}^{-1}$. Finally, the performance of the fabricated device was demonstrated in a self-powered system by integrating the fiber supercapacitor with dye sensitized solar cells (DSSCs) to drive a light emitting diode (LED). These promising results demonstrate that flexible fiber supercapacitors have great potential for embedding in flexible electronics, such as portable and wearable devices, and self-powered devices.

\section{Results and discussion}

The fabrication process of the $3 \mathrm{D}-\mathrm{NiCo}_{2} \mathrm{O}_{4} / \mathrm{Ni}$ nanostructure involved three steps, as schematically illustrated in Fig. 1. First,
3D-Ni was constructed on a Ni-wire current collector via facile electrochemical deposition accompanied by a hydrogen evolution reaction..$^{\mathbf{2 0 , 2 1}}$ Here, hydrogen bubbles play a crucial role in forming a 3D porous structure. At a high applied current $(2.5 \mathrm{~A})$, plentiful hydrogen bubbles were formed over the Ni-wire (cathode) surface via a water electrolysis reaction. At the same time, $\mathrm{Ni}^{2+}$ ions were electrochemically reduced and deposited over the Ni-wire by using the hydrogen bubbles as a template for the construction of a 3D-porous-Ni structure with dendritic walls on the Ni-wire substrate. Since the hydrogen bubbles not only arise from the substrate but also from freshly deposited nickel, they serve as a dynamic template for the formation of dendritic 3D-Ni. ${ }^{20}$ The as-prepared 3D-Ni is much more effective than the traditional Ni foam current collectors due to its highly porous dendritic morphology, with high surface area, open porous structure and a facile preparation technique that allows for any arbitrary shape structure.

In the second step, a green colour bimetallic (Ni, Co) hydroxide was co-electrodeposited onto the 3D-Ni. Briefly, the electrodeposition process of the mixed hydroxide formation involved an electrochemical and a precipitation reaction. When electric current passes through the electrolyte containing nickel and cobalt nitrate precursors, $\mathrm{OH}^{-}$ions are produced by the reduction of $\mathrm{NO}_{3}{ }^{-}$ions at the cathodic surface. Then the generated $\mathrm{OH}^{-}$ions in the solution will react with $\mathrm{Ni}^{2+}$ and $\mathrm{Co}^{2+}$ to form a uniform precipitate of mixed hydroxide on the $3 \mathrm{D}-\mathrm{Ni}$ electrode surface; the overall reaction process can be expressed as follows: $:^{22,23}$

$$
\begin{gathered}
\mathrm{NO}_{3}{ }^{-}+7 \mathrm{H}_{2} \mathrm{O}+8 \mathrm{e}^{-} \rightarrow \mathrm{NH}_{4}^{+}+10 \mathrm{OH}^{-} \\
x \mathrm{Ni}^{2+}+2 x \mathrm{Co}^{2+}+6 x \mathrm{OH}^{-} \rightarrow \mathrm{Ni}_{x} \mathrm{CO}_{2 x}(\mathrm{OH})_{6 x}
\end{gathered}
$$

Finally, the as-prepared bimetallic hydroxide was calcined at $300{ }^{\circ} \mathrm{C}$ for $2 \mathrm{~h}$ (thermal transformation) to yield spinel $\mathrm{NiCO}_{2} \mathrm{O}_{4}$, as shown in the following equation:

$$
2 \mathrm{Ni}_{x} \mathrm{Co}_{2 x}(\mathrm{OH})_{6 x}+x \mathrm{O}_{2} \rightarrow 2 x \mathrm{NiCo}_{2} \mathrm{O}_{4}+6 x \mathrm{H}_{2} \mathrm{O}
$$

We have deposited the $\mathrm{NiCo}_{2} \mathrm{O}_{4}$ nanostructure on the 3D-Ni wire at various deposition times of 3,5 , and $10 \mathrm{~min}$. In the case of the 3 and 5 minute-deposited samples, no peel off problem occurred while drying the samples (please refer to Fig. S1†).
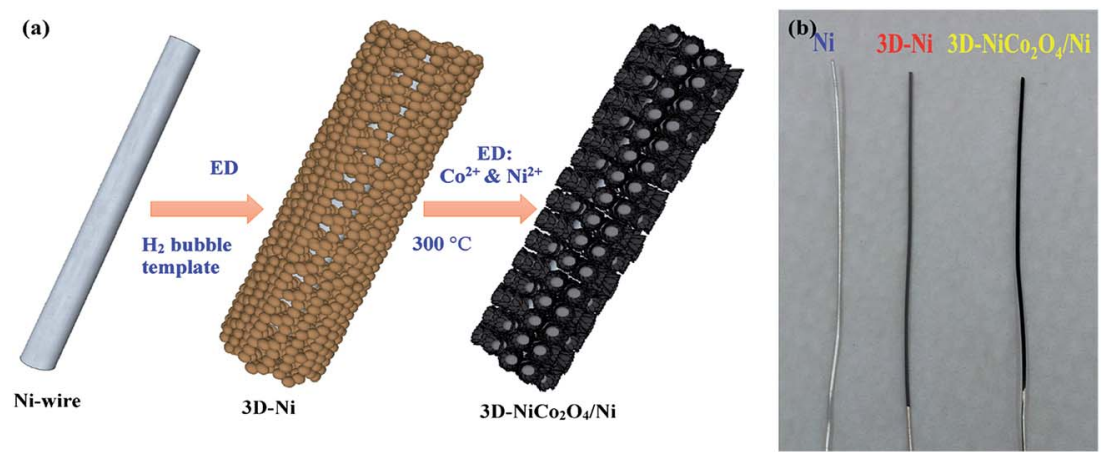

Fig. 1 (a) Schematic illustration of the preparation of 3D-NiCo $\mathrm{O}_{4} / \mathrm{Ni}$. (b) Digital camera image of the $\mathrm{Ni}-$ wire, 3D-Ni and $3 \mathrm{D}-\mathrm{NiCO} \mathrm{O}_{4} / \mathrm{Ni}$. Electrodeposition is indicated as "ED". 
However, when the electro-deposition time was increased beyond $5 \mathrm{~min}$, the as-deposited bimetallic hydroxide started to peel off (detached) from 3D-Ni during the drying process. This might be due to the higher mass loading of electro-active materials in a small area, which leads to less adhesion between the porous electrode and the bimetallic hydroxide electro-active materials.

The as-prepared $3 \mathrm{D}$ porous flower-like $\mathrm{NiCo}_{2} \mathrm{O}_{4} / \mathrm{Ni}$ nanostructure (3D- $\mathrm{NiCo}_{2} \mathrm{O}_{4} / \mathrm{Ni}$ ) was directly used to provide binderand conductive agent-free electrodes for supercapacitors. Fig. 1b shows a digital photograph of the bare Ni-wire and the synthesized $3 \mathrm{D}-\mathrm{Ni}$ and $3 \mathrm{D}-\mathrm{NiCo}_{2} \mathrm{O}_{4} / \mathrm{Ni}$. Compared to the silvery $\mathrm{Ni}$-wire in the left side, the $3 \mathrm{D}-\mathrm{Ni}$ and $3 \mathrm{D}-\mathrm{NiCo}_{2} \mathrm{O}_{4} / \mathrm{Ni}$ appear brown and black due to the presence of the porous 3D-nanostructures with submicron scale dimensions, which effectively interact with light. ${ }^{24,25}$ Three as-prepared 3D porous $\mathrm{NiCo}_{2} \mathrm{O}_{4}$ nanostructures on the $3 \mathrm{D}-\mathrm{Ni}$ samples fabricated at electrodeposition times of 3-, 5-, and $10 \mathrm{~min}$ were named 3D-NCO/Ni-1, 3D-NCO/Ni-2, and 3D-NCO/Ni-3, respectively.

\section{Morphological analysis}

The morphologies of the pure Ni-wire, the 3D-Ni on Ni-wire and $3 \mathrm{D}-\mathrm{NiCo}_{2} \mathrm{O}_{4} / 3 \mathrm{D}$-Ni on $\mathrm{Ni}$ wire were examined by FE-SEM. The detailed structural and compositional analyses including X-ray diffraction, Raman, X-ray photoelectron and energy dispersive $\mathrm{X}$-ray spectroscopy are found in Fig. S2-S4. $\dagger$ Fig. 2a shows the
FE-SEM images of the pristine Ni-wire which has a smooth surface. Fig. 2b-c depict the typical 3D porous interconnected $\mathrm{Ni}$ dendritic walls over the $\mathrm{Ni}$-wire $(3 \mathrm{D}-\mathrm{Ni} / \mathrm{Ni}$ ) created by the dynamic hydrogen template method. It can be observed that the $3 \mathrm{D}$ porous Ni structure consists of large pores of $\sim 4-8 \mu \mathrm{m}$ decorated by numerous interconnected nanoparticles $(\sim 150-350 \mathrm{~nm})$, displaying continuous interspaces (lots of interconnected nanopores of $\sim 25-150 \mathrm{~nm}$ ) in the form of dendritic walls. Plain view $\mathrm{SEM}$ images of $3 \mathrm{D}-\mathrm{NiCO}_{2} \mathrm{O}_{4} / 3 \mathrm{D}-\mathrm{Ni}$ (3D-NCO/Ni-2) are shown in Fig. 2e, f, h and i. FE-SEM images of 3D-NCO/Ni-1 and 3D-NCO/ Ni-3 samples are shown in Fig. S5a-d. $\dagger$ Numerous $\mathrm{NiCo}_{2} \mathrm{O}_{4}$ nanoflakes with thicknesses in the range of $\sim 20-30 \mathrm{~nm}$ can be seen to decorate the $3 \mathrm{D}-\mathrm{Ni}$, creating a rough surface, as shown in Fig. 2e, f, h and i. The $\mathrm{NiCo}_{2} \mathrm{O}_{4}$ nanoflakes are interconnected with each other over the Ni surface, which produces a highly porous dendritic flower-like $\mathrm{NiCo}_{2} \mathrm{O}_{4} / 3 \mathrm{D}-\mathrm{Ni}$ structure with microspheres $(\sim 1 \mu \mathrm{m})$. The $3 \mathrm{D}$ porous interconnected dendritic structure was produced by the deposition of $\mathrm{NiCo}_{2} \mathrm{O}_{4}$ and the thermal treatment. However, a long electrodeposition time, over $10 \mathrm{~min}$, caused the cracking or detachment of $\mathrm{NiCo}_{2} \mathrm{O}_{4}$ from the 3D-Ni during the drying process. Since our results concluded that 5 min was the optimum time to deposit $\mathrm{NiCO}_{2} \mathrm{O}_{4}$ over $3 \mathrm{D}-\mathrm{Ni}$, further studies were conducted on the $3 \mathrm{D}-\mathrm{NCO} / \mathrm{Ni}-2$. The crosssection view of the $3 \mathrm{D}-\mathrm{NCO} / \mathrm{Ni}-2$ is presented in Fig. $2 \mathrm{~d}$ and $\mathrm{g}$. The thickness of the 3D-NCO/Ni is approximately $\sim 35 \mu \mathrm{m}$ as shown in Fig. $2 \mathrm{~g}$. Further, it is clear that the numerous small-ramified
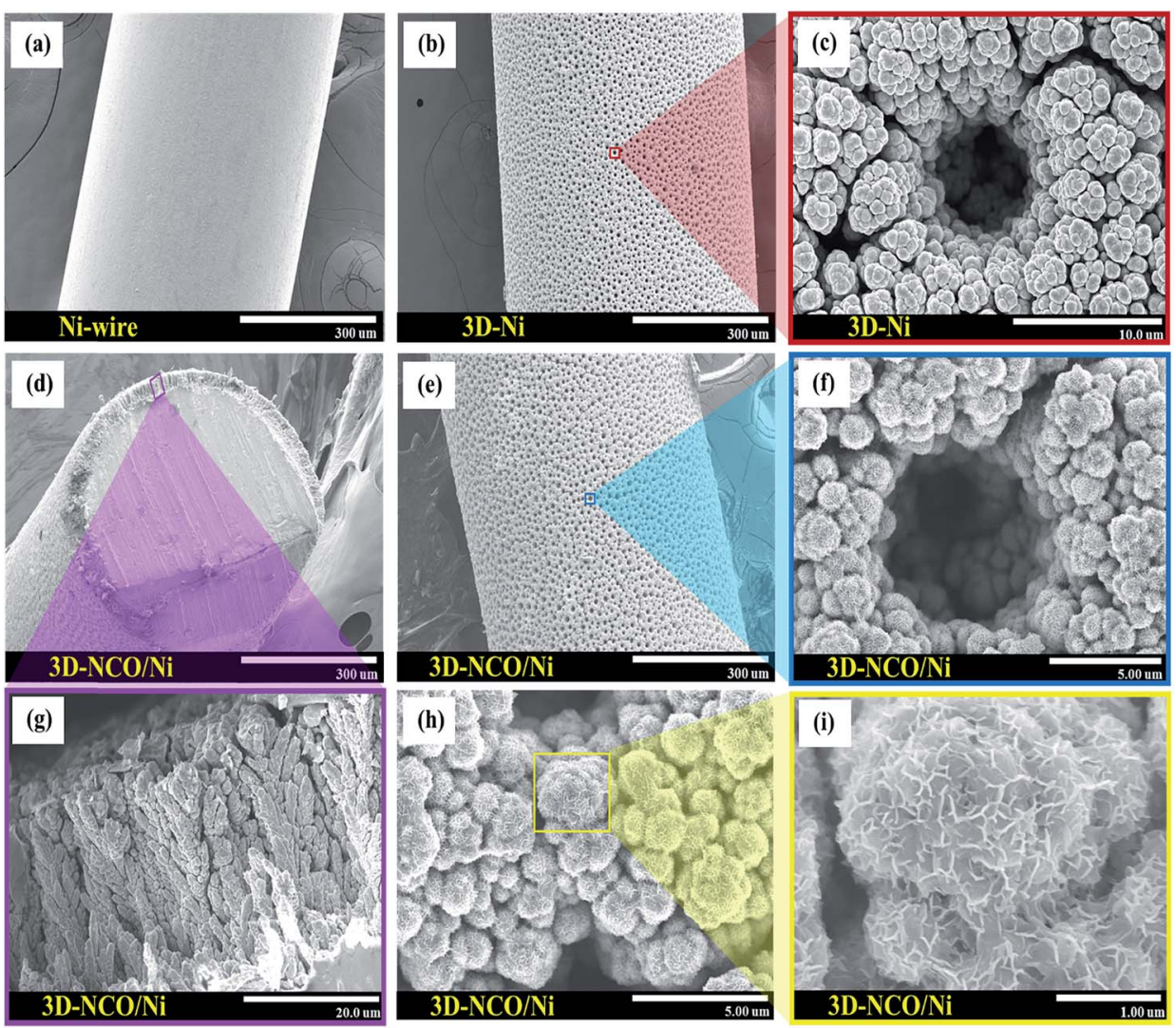

Fig. 2 FE-SEM images of (a) Ni-wire, (b-c) 3D-Ni, and (d-i) 3D-NiCo $\mathrm{O}_{4} / 3 \mathrm{D}-\mathrm{Ni}$ : (d, g) cross-section image. (e) Plain view images. (f-i) High magnification images. 
deposits (Ni nanoparticles) are arranged normal to the substrate and form a porous dendritic wall structure, leaving lots of open spaces and electroactive surface sites. In addition, the FE-SEM images (Fig. S6a-f $\dagger$ ) of $3 \mathrm{D}$ - $\mathrm{NiCo}_{2} \mathrm{O}_{4} / \mathrm{Ni}$-wire clearly show uniform morphology without any damage, which confirms excellent mechanical stability (remains stable under a bending condition of $90^{\circ}$ ) as well as the flexibility of our fabricated $3 \mathrm{D}-\mathrm{NiCo}_{2} \mathrm{O}_{4} / \mathrm{Ni}-$ wire electrode.

From the above results, we expected that the construction of $3 \mathrm{D}-\mathrm{NiCo}_{2} \mathrm{O}_{4} / 3 \mathrm{D}-\mathrm{Ni}$ would promote excellent supercapacitor electrochemical performance, including high capacitance, better rate capability, and longer cycling life. The advantages of $3 \mathrm{D}-\mathrm{NiCo}_{2} \mathrm{O}_{4} / 3 \mathrm{D}-\mathrm{Ni}$ are that (i) they use no conductive additive, (ii) the enlarged active surface area allows for efficient contact with the electrolytes, (iii) the large size open pores facilitate the diffusion of electrolytes, and (iv) low resistance due to the short path distance for electron transport is achieved by direct contact between the active materials and the interconnected 3D-Ni networks.

\section{Electrochemical evaluation of $3 \mathrm{D}-\mathrm{NiCo}_{2} \mathrm{O}_{4} / \mathrm{Ni}$}

The pseudocapacitive properties of the Ni-wire, 3D-Ni/Ni-wire and $3 \mathrm{D}-\mathrm{NiCO}_{2} \mathrm{O}_{4} / 3 \mathrm{D}-\mathrm{Ni} / \mathrm{Ni}$-wire (3D-NCO/Ni-1, 3D-NCO/Ni-2 and $3 \mathrm{D}-\mathrm{NCO} / \mathrm{Ni}-3$ ) were evaluated by using a three electrode system in a $2 \mathrm{M} \mathrm{KOH}$ electrolyte solution and the results are shown in Fig. 3. The cyclic voltammetry (CV) curves of the bare Ni-wire, 3D-Ni/Ni-wire, 3D-NCO/Ni-1, 3D-NCO/Ni-2 and 3D$\mathrm{NCO} / \mathrm{Ni}-3$ electrodes at a scan rate of $10 \mathrm{mV} \mathrm{s}^{-1}$ in a potential window of -0.2 to $0.55 \mathrm{~V}$ are presented in Fig. 3a. The bare Niwire and $3 \mathrm{D}-\mathrm{Ni} / \mathrm{Ni}$-wire exhibit one pair of redox peaks, implying the highly reversible reactions of $\mathrm{Ni}^{2+} / \mathrm{Ni}^{3+}$. The $\mathrm{CV}$ curves of the 3D-NCO/Ni samples display two pairs of redox peaks of $\mathrm{NiCo}_{2} \mathrm{O}_{4}$ during the electrochemical process. The two sets of redox peaks are attributed to the reversible faradaic redox processes of $\mathrm{Ni}^{2+} / \mathrm{Ni}^{3+}$ and $\mathrm{Co}^{2+} / \mathrm{Co}^{3+}$ transitions. ${ }^{26-28}$ In comparison to the $\mathrm{Ni}$-wire and $3 \mathrm{D}-\mathrm{Ni}$, the $3 \mathrm{D}-\mathrm{NiCo}_{2} \mathrm{O}_{4} / \mathrm{Ni}$ electrodes exhibited a larger $\mathrm{CV}$ integrated area (increased redox current intensity), suggesting that a much higher electrochemical performance was achieved by the $3 \mathrm{D}-\mathrm{NiCo}_{2} \mathrm{O}_{4}$
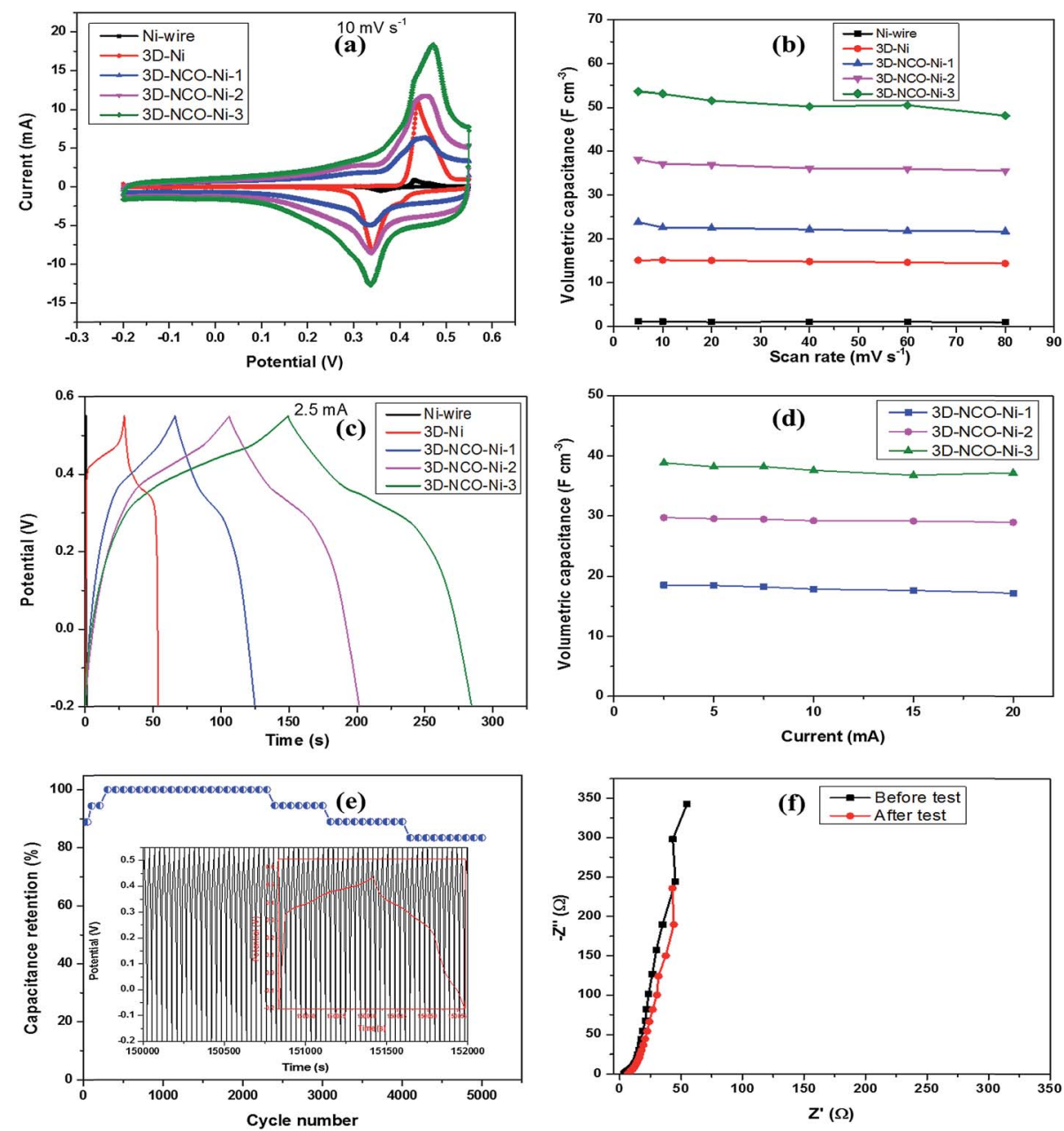

Fig. 3 (a) CV curves of $\mathrm{Ni}, 3 \mathrm{D}-\mathrm{Ni}, 3 \mathrm{D}-\mathrm{NCO} / \mathrm{Ni}-1,3 \mathrm{D}-\mathrm{NCO} / \mathrm{Ni}-2$ and 3D-NCO/Ni-3 electrodes in $2 \mathrm{M}$ KOH electrolyte solutions. (b) Volumetric capacitance of $\mathrm{Ni}, 3 \mathrm{D}-\mathrm{Ni}, 3 \mathrm{D}-\mathrm{NCO} / \mathrm{Ni}-1,3 \mathrm{D}-\mathrm{NCO} / \mathrm{Ni}-2$ and 3D-NCO/Ni-3 electrodes at different scan rates. (c) Galvanostatic charge/discharge curves of $\mathrm{Ni}, 3 \mathrm{D}-\mathrm{Ni}, 3 \mathrm{D}-\mathrm{NCO} / \mathrm{Ni}-1,3 \mathrm{D}-\mathrm{NCO} / \mathrm{Ni}-2$ and 3D-NCO/Ni-3 electrodes at $2.5 \mathrm{~mA}$. (d) Volumetric capacitances of 3D-NCO/Ni-1, 3D-NCO/Ni-2 and 3D-NCO/Ni-3 electrodes as a function of current. (e) Cycling performance of the 3D-NCO/Ni-2 electrode at a current of $10 \mathrm{~mA}$; the inset shows the charge/discharge curves. (f) Nyquist plots of the 3D-NCO/Ni-2 electrode before and after the 5000 cycle test. 
active materials. In particular, the $3 \mathrm{D}-\mathrm{NCO} / \mathrm{Ni}-3$ showed the highest redox current intensity among the $\mathrm{NiCo}_{2} \mathrm{O}_{4}$ electrodes, which was attributed to its having the largest loading mass of electroactive materials. The representative $\mathrm{CV}$ profiles of the $3 \mathrm{D}-\mathrm{NCO} / \mathrm{Ni}$ at various scan rates ranging from 5 to $80 \mathrm{mV} \mathrm{s}^{-1}$ are displayed in Fig. S7a-c. $\dagger$ Further, the EIS measurements were also carried out for Ni-wire, 3D-Ni, 3D-NCO/Ni-1, 3D-NCO/ $\mathrm{Ni}-2$ and $3 \mathrm{D}-\mathrm{NCO} / \mathrm{Ni}-3$ electrodes to investigate the fundamental behavior of the fabricated electrodes, and the corresponding Nyquist plots are shown in Fig. S8a and b. $\dagger$

Fig. $3 \mathrm{~b}$ shows the volumetric capacitance of the $3 \mathrm{D}-\mathrm{NCO} / \mathrm{Ni}$ electrodes at different scan rates, calculated from the CV curves by using the total volume of the electrode including the Ni-wire, $3 \mathrm{D}-\mathrm{Ni}$ and the electroactive material $\left(\mathrm{NiCo}_{2} \mathrm{O}_{4}\right)$, and by using eqn (1), (3), and (4) (Section G in the ESI $\dagger$ ). The volumetric capacitance of the Ni-wire, the 3D-Ni, 3D-NCO/Ni-1, 3D-NCO/Ni2 and $3 \mathrm{D}-\mathrm{NCO} / \mathrm{Ni}-3$ electrodes is found to be 1.18, 15.14, 23.79, 38.16, and $53.66 \mathrm{~F} \mathrm{~cm}^{-3}$, respectively, at $5 \mathrm{mV} \mathrm{s}^{-1}$. With increasing scan rate, the capacitance of the $3 \mathrm{D}-\mathrm{NCO} / \mathrm{Ni}-1$, $3 \mathrm{D}-\mathrm{NCO} / \mathrm{Ni}-2$ and 3D-NCO/Ni-3 electrodes still retained 91\%, $93 \%$ and $89 \%$ of the initial capacitance even at a high scan rate of $80 \mathrm{mV} \mathrm{s}^{-1}$, respectively, which indicates the high-rate capability of the fabricated electrodes. The gravimetric capacitance of the 3D-NCO/Ni electrodes was calculated using only the mass of the electroactive material $\left(\mathrm{NiCO}_{2} \mathrm{O}_{4}\right)$, excluding the mass of 3D-Ni and Ni-wire. The calculated gravimetric capacitance (Fig. S9a $\dagger$ ) of the 3D-Ni, 3D-NCO/Ni-1, 3D-NCO/Ni-2 and $3 \mathrm{D}-\mathrm{NCO} / \mathrm{Ni}-3$ electrodes is $11,300,385$, and $443 \mathrm{~F} \mathrm{~g}^{-1}$, respectively. The calculated areal capacitance of the electrodes is shown in Fig. S9b. $\dagger$

Fig. 3c displays the comparative galvanostatic charge/ discharge (GCD) curves of the bare Ni-wire, the 3D-Ni, 3D-NCO/ $\mathrm{Ni}-1,3 \mathrm{D}-\mathrm{NCO} / \mathrm{Ni}-2$ and $3 \mathrm{D}-\mathrm{NCO} / \mathrm{Ni}-3$ electrodes, performed in a stable potential window between -0.2 and 0.55 at a current of $2.5 \mathrm{~mA}$. Fig. 3d shows the volumetric capacitance of the $3 \mathrm{D}-\mathrm{NiCo}_{2} \mathrm{O}_{4} / \mathrm{Ni}$ electrodes as a function of current (Fig. S7d-f $\dagger$ display the GCD curves of the 3D-NCO/Ni-1, 3D-NCO/Ni-2 and 3D-NCO/Ni-3 electrodes at different current densities ranging from 2.5 to $20 \mathrm{~mA}$, which is consistent with the $\mathrm{CV}$ results). As expected, 3D-NCO/Ni-3 delivered a higher capacitive performance than the other electrodes (3D-NCO/Ni-1 and $3 \mathrm{D}-\mathrm{NCO} / \mathrm{Ni}-$ 2) because a higher proportion of the $3 \mathrm{D}-\mathrm{NiCo}_{2} \mathrm{O}_{4}$ was supported by the advantageous $3 \mathrm{D}$ nature of the $3 \mathrm{D}-\mathrm{Ni}$. The volumetric capacitance of the Ni-wire, 3D-Ni, 3D-NCO/Ni-1, 3D-NCO/Ni-2 and 3D-NCO/Ni-3 electrodes at a current of $2.5 \mathrm{~mA}$ was $0.38,3.4$, 18.5, 29.7, and $38.84 \mathrm{~F} \mathrm{~cm}^{-3}$, respectively. Similarly, the maximum gravimetric capacitances (Fig. S9c $\dagger$ ) of 3D-NCO/Ni-3, 3D-NCO/Ni-2 and 3D-NCO/Ni-1 were 336, 300, and $233 \mathrm{~F} \mathrm{~g}^{-1}$, respectively, with a capacitance retention of 95.5, 97.5 and $93.1 \%$ as the current was increased from 2.5 to $20 \mathrm{~mA}$. The achieved specific capacitance $\left(C_{\mathrm{v}}, C_{\mathrm{a}}\right.$, and $\left.C_{\mathrm{g}}\right)$ was significantly higher than that of previously reported fiber electrodes, such as a $\mathrm{MnO}_{2} /$ graphene/carbon fibre and graphene hydrogel wrapped copper wire $\left(13.7 \mathrm{~F} \mathrm{~cm}^{-3}\right.$, and $73 \mathrm{~F} \mathrm{~cm}^{-3}$ at $\left.0.5 \mathrm{~mA} \mathrm{~cm}^{-2}\right),{ }^{29}$ a MWCNTs/ $\mathrm{CMF}\left(14.1 \mathrm{~F} \mathrm{~cm}^{-3}\right.$ at $\left.5 \mathrm{mV} \mathrm{s}^{-1}\right),{ }^{30} \mathrm{Ni}(\mathrm{OH})_{2}$ nanowire fibre and ordered mesoporous carbon fibre electrode $\left(270 \mathrm{~F} \mathrm{~g}^{-1}\right.$ and $76.7 \mathrm{~F}$ $\mathrm{g}^{-1}$ at $\left.0.5 \mathrm{~mA}\right),{ }^{31} \mathrm{MnO}_{2} /$ carbon nanoparticles/carbon fiber and functionalize carbon nanoparticles/carbon fiber $\left(27.5 \mathrm{~F} \mathrm{~cm}^{-3}\right.$ and $22.5 \mathrm{~F} \mathrm{~cm}^{-3}$ at $5 \mathrm{mV} \mathrm{s}^{-1}$ ), ${ }^{32}$ hydrogenated single crystal ZnO@amorphous $\mathrm{ZnO}$-doped $\mathrm{MnO}_{2}$ core-shell nanocable (138.7 $\mathrm{mF} \mathrm{cm}^{-2}$ at $\left.1 \mathrm{~mA} \mathrm{~cm}{ }^{-2}\right),{ }^{33} \mathrm{TiO}_{2} @ \mathrm{C}\left(31.3 \mathrm{mF} \mathrm{cm}^{-2}\right.$ at $\left.10 \mathrm{mV} \mathrm{s}^{-1}\right)^{34}$ and graphene/polypyrrole (G/PPy) composite fibers $\left(115 \mathrm{mF} \mathrm{cm}^{-2}\right.$ at $\left.0.2 \mathrm{~mA} \mathrm{~cm}^{-2}\right) .^{35}$

The excellent electrochemical performance of the conductive additive and binder-free $3 \mathrm{D}-\mathrm{NiCo}_{2} \mathrm{O}_{4} / 3 \mathrm{D}-\mathrm{Ni}$ electrode can be attributed to the following reasons. ${ }^{36-39}$ First, because the $\mathrm{NiCo}_{2} \mathrm{O}_{4}$ nanoflakes are directly grown on the 3D-Ni nanoframe, they can form a better electrical connection with, and better mechanical adhesion to, the 3D-Ni current collector, leading to a reduction in contact resistance as well as efficient current collection and fast electron transport between individual $\mathrm{NiCo}_{2} \mathrm{O}_{4}$ nanoflakes and the $3 \mathrm{D}-\mathrm{Ni}$. Second, the $3 \mathrm{D}$ porous structure offers adequate open spaces, and thus the electrolyte can easily penetrate through this structure for efficient redox reactions during the faradaic charge storage process, inducing high utilization of the electroactive material. Third, the high surface area of the $3 \mathrm{D}-\mathrm{NiCo}_{2} \mathrm{O}_{4} / \mathrm{Ni}$ architecture provides a large density of active sites involved in electrochemical reactions.

However, compared with 3D-NCO/Ni-2, the 3D-NCO/Ni-3 exhibits inferior rate capability when characterized under similar conditions. This may be due to the existence of the peeloff issue, as described in the previous section (Fig. 1 and $\mathrm{S} 1 \dagger$ ). The non-uniform, constrained pores and deprived adhesion of electroactive materials from the current collector (some active materials are peeled off from the current collector) limited the diffusion rate of the electrolyte ions to the interior part of the electrode surface at higher charge/discharge rates, and therefore only the outer surface of the electroactive materials was utilized for energy storage, which leads to lower performance. From our results, we concluded that $3 \mathrm{D}-\mathrm{NCO} / \mathrm{Ni}-2$ exhibited better electrochemical performance than the other electrodes studied here. Hence, further electrochemical studies were conducted only on 3D-NCO/Ni-2 electrodes.

The electrochemical stability of the $3 \mathrm{D}-\mathrm{NiCo}_{2} \mathrm{O}_{4} / \mathrm{Ni}$ electrode was examined by a repeated charging/discharging process for more than 5000 cycles at a constant current of $10 \mathrm{~mA}$, as shown in Fig. 3e. The cycling performance of the as-prepared $3 \mathrm{D}-\mathrm{NiCo}_{2} \mathrm{O}_{4} / \mathrm{Ni}$ electrode consists of three processes: (i) electroactivation, (ii) steady state, and (iii) a degradation stage. At the first stage of the electro-activation process, the specific capacitance gradually increases from the $1^{\text {st }}$ cycle $(88.8 \%)$ to 300 cycles and reaches the maximum value of $100 \%$ and then the specific capacitance remained constant from 300 to 2400 cycles (100\%). At the last stage, the specific capacitance started to decrease gradually for the subsequent 2600 cycles. At the final stage, the cycling stability of $3 \mathrm{D}-\mathrm{NCO} / \mathrm{Ni}$ is fairly stable and $80 \%$ of the specific capacitance is still retained even after 5000 cycles. The charge/discharge curves of the 3D-NCO/Ni-2 electrode in the inset retain a symmetrical shape even after the long-term cycle test. These results confirm that the 3D-NCO/Ni electrode not only has high capacitance but also has excellent cycling stability at high current, which is one of the important criteria for practical applications. 
The initial increase of specific capacitance is mainly due to the electro-activation process of the electroactive materials. ${ }^{\mathbf{4 0 , 4 1}}$ During the first few cycles only some of the materials are active, whereas upon increasing the number of cycles as well as time, more efficient soaking of the electroactive materials with the liquid $2 \mathrm{M} \mathrm{KOH}$ electrolyte further activated the bulk part of the electroactive materials, because the 3D-porous-Ni dendritic wall structure is formed by numerous interconnected nanoparticles with large pores on the Ni-wire substrate. Further, the numerous $\mathrm{NiCo}_{2} \mathrm{O}_{4}$ nanoflakes are interconnected with each other over the $3 \mathrm{D}-\mathrm{Ni}$ surface. Hence, the penetration of the electrolyte into the whole surface including small-ramified deposits requires a certain period of time. As the electrolyte slowly penetrates the entire $3 \mathrm{D}-\mathrm{NCO} / \mathrm{Ni}$ nanostructure, more and more of the bulk part of the electroactive materials becomes active and contributes to the increase in specific capacitance. In addition, the increase of specific capacitance might also originate from the 3D-Ni current collector by the in situ conversion of 3D-Ni into nickel hydroxide and in turn further incorporation of $\mathrm{Ni}(\mathrm{OH})_{2}$ into $\mathrm{NiCo}_{2} \mathrm{O}_{4}$ during the longterm electrochemical cycling process. ${ }^{21,42}$

Further, to investigate changes in resistance, EIS analysis was performed before and after the 5000 cycle tests in a frequency range of $100 \mathrm{kHz}$ to $0.1 \mathrm{~Hz}$ at an open circuit potential with an AC perturbation of $10 \mathrm{mV}$. As shown in Fig. 3f, both impedance spectra are almost similar in shape with an arc shape in the high frequency region and a straight line in the low frequency region, which once again demonstrates stable capacitive behavior. A slight increase of $R_{\mathrm{i}}(2.2 \Omega)$ and $R_{\mathrm{ct}}(0.5 \Omega)$ after 5000 cycles may be due to the loss of some electroactive materials during the charge/discharge process. ${ }^{\mathbf{4 3 , 4 4}}$

\section{Electrochemical evaluation of the solid state symmetric supercapacitor}

Based on the remarkable electrochemical behaviour of the optimal 3D-NiCo $\mathrm{O}_{4} / 3 \mathrm{D}-\mathrm{Ni}$ electrode (3D-NCO/Ni-2), we fabricated a flexible solid state supercapacitor using two identical 3D-NCO/Ni-2 electrodes as the positive and negative electrodes, with PVA-KOH as a gel electrolyte on a PET substrate, for practical applications in flexible devices. The electrodes were assembled parallel in the PET substrate with a separation distance of $1 \mathrm{~mm}$ to reduce the leakage current of the supercapacitors. Fig. 4a presents the typical $\mathrm{CV}$ curves of the flexible solid state 3D-NCO/Ni//3D-NCO/Ni symmetric fiber supercapacitor at different scan rates between 0 and $1 \mathrm{~V}$, implying ideal pseudocapacitive behaviour. With increasing scan rate, the current density increases without obvious distortion in shape of the curves, which confirms the good rate capability of the device and efficient ionic transport within the electrode materials. The gravimetric and volumetric capacitances (Fig. S10 $\dagger$ ) of the device are $30 \mathrm{~F} \mathrm{~g}^{-1}$ and $3 \mathrm{~F} \mathrm{~cm}^{-3}$ at a scan rate of $5 \mathrm{mV} \mathrm{s}^{-1}$, respectively, and it still retains $45 \%$ of initial capacitance at a high scan rate of $100 \mathrm{mV} \mathrm{s}^{-1}$. Compared to the gravimetric performance, volumetric performance is considered to be a more reliable and accurate metric for assessing the energy-storage capacity of supercapacitors for practical applications, especially when the supercapacitors are employed in a limited space such as miniaturized, portable, flexible, and wearable electronics, electric vehicles, and micro-/nano-electromechanical systems. When the scan rate is increased from 5 to $100 \mathrm{mV} \mathrm{s}^{-1}$, the solid-state fiber supercapacitor showed a lower specific capacitance and rate capability. This may be attributed to the poor ionic conductivity of the solid electrolyte (when compared to the liquid electrolyte based supercapacitors) and the kinetic limitation of electrolyte ion diffusion in solid state devices. ${ }^{45,46}$

The GCD curves of the flexible solid state fiber supercapacitor at different currents are shown in Fig. 4b. All the charge/discharge curves reveal good symmetry and are linear in nature, which confirms that the device has excellent electrochemical reversibility and capacitive behaviour. The gravimetric and volumetric capacitances (Fig. S10 ${ }^{\dagger}$ ) of the flexible fiber supercapacitor calculated from charge/discharge curves are $18.8 \mathrm{~F} \mathrm{~g}^{-1}$ and $1.86 \mathrm{~F} \mathrm{~cm}^{-3}$ at a current of $0.1 \mathrm{~mA}$, and retain $8.29 \mathrm{~F} \mathrm{~g}^{-1}$ and $0.82 \mathrm{~F} \mathrm{~cm}^{-3}$ even at a high current of $1 \mathrm{~mA}$, which reveals the good rate-capability of the device. The volumetric and gravimetric capacitances of a single electrode are $7.45 \mathrm{~F}$ $\mathrm{cm}^{-3}$ and $75.3 \mathrm{~F} \mathrm{~g}^{-1}$, respectively. The achieved specific capacitance is higher than earlier reported values for fiber based solid state supercapacitors, such as $\mathrm{NiCo}_{2} \mathrm{O}_{4} / \mathrm{Ni}$ wire-SCs $\left(10.3 \mathrm{~F} \mathrm{~cm}^{-3}\right),{ }^{14} \mathrm{CuCo}_{2} \mathrm{O}_{4} / \mathrm{Ni}$ wire-SCs $\left(11.09 \mathrm{~F} \mathrm{~g}^{-1}\right),{ }^{15} \mathrm{ZnCo}_{2} \mathrm{O}_{4} /$ Ni-wire-SCs $\left(10.9 \mathrm{~F} \mathrm{~g}^{-1}\right.$ ) ${ }^{16}$ and $\mathrm{ZnCo}_{2} \mathrm{O}_{4}$ nanowire array/carbon fiber $\left(0.6 \mathrm{~F} \mathrm{~g}^{-1}\right)$ supercapacitors. ${ }^{17}$

The rate capability and long-term cyclic stability are the most vital characteristics for energy storage devices. The rate capability of the fiber supercapacitor was measured at different currents from 0.2 to $1 \mathrm{~mA}$ for 100 cycles, as shown in Fig. 4c. The device exhibits good rate capability and shows almost stable capacitance at each current. The device retains around 55\% of the initial capacitance at a discharge current of $0.1 \mathrm{~mA}$, and even the discharge current was increased by 10 -fold after 500 cycles, which indicates that the device has excellent rate capability. Second, the electrochemical stability of the fiber supercapacitor was examined using a repeated GCD test at a current of $0.8 \mathrm{~mA}$ for 5000 cycles (Fig. 4d). The symmetric device exhibited excellent cycling stability with a capacitance retention around $100 \%$ as the cycle number increased, even after 5000 cycles. The inset of Fig. 4d shows the charge/discharge curves of the device, indicating that most curves display linear and symmetrical shapes, confirming excellent cycling stability with no significant structural change during the charge/discharge processes.

The electrochemical performance of the fiber supercapacitor was further evaluated using EIS measurements in the frequency range from $10 \mathrm{mHz}$ to $100 \mathrm{kHz}$ with an AC perturbation of $10 \mathrm{mV}$. As shown in the Nyquist plots of the fiber supercapacitor (Fig. 4e) the equivalent series resistance $\left(R_{\mathrm{S}}\right)$ of the device exhibits a small value of $3.2 \Omega$, and small charge transfer resistance in the high frequency region (inset Fig. 4e), indicating that the device possesses small internal resistance and good conductivity due to the porous nature, which facilitates faster ionic and electronic movement. Moreover, a straight line in the low frequency region reveals the ideal capacitive behavior of the fiber supercapacitor. 

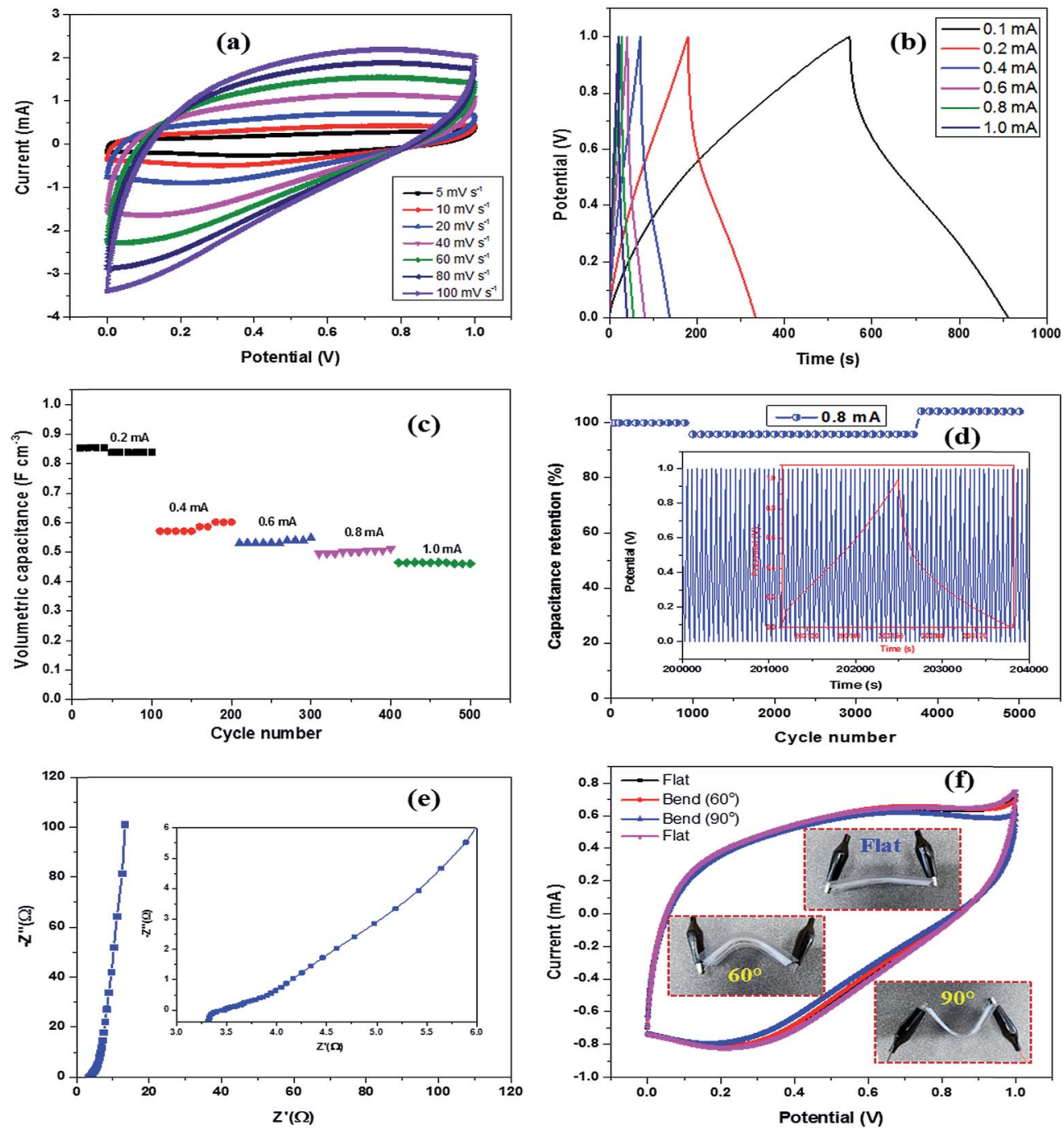

Fig. 4 Electrochemical evaluation of the 3D-NCO/Ni//3D-NCO/Ni solid state symmetric device. (a) Cyclic voltammetry curves of the solid state symmetric device as a function of scan rate. (b) Galvanostatic charge/discharge voltage profiles at different currents. (c) Cycling performance of the 3D-NCO/Ni//3D-NCO/Ni symmetric fiber supercapacitor with increasing currents. (d) Cycling performance of the fiber supercapacitor measured at a constant current of $0.8 \mathrm{~mA}$; the inset displays the charge/discharge curves at $0.8 \mathrm{~mA}$. (e) Nyquist plot of the symmetric device; the inset shows the magnified plot in the high-frequency region. (f) CV curves of the fiber supercapacitor at different bending states; the inset shows the digital camera images of the device at different bending states.

Fig. 4f shows the CV curves of the flexible fiber supercapacitor under different bending conditions at a scan rate of $50 \mathrm{mV} \mathrm{s}^{-1}$. The shapes of all the $\mathrm{CV}$ curves including flat, bent $\left(60^{\circ}\right.$ and $\left.90^{\circ}\right)$ and recovery conditions were almost similar to one another, indicating the excellent mechanical stability of our fabricated device for flexible energy storage systems. The inset of Fig. $4 \mathrm{f}$ displays digital photos of our fabricated devices under flat and bent $\left(60^{\circ}\right.$ and $\left.90^{\circ}\right)$ conditions, indicating that the fabricated device has high flexibility and bendability which could be utilized in portable electronics such as flexible and wearable devices.

To consider the performance of the fabricated supercapacitors in real-world applications, it is necessary to connect fiber supercapacitors either in series or in parallel, or in a combination of both, to boost the ability (operating voltage and/or current) of the supercapacitor for powering various portable electronic devices. Therefore, the feasibility of the integrated supercapacitors was further tested with them connected in series and parallel configurations. A schematic illustration of the three fiber supercapacitors assembled on a PET substrate is shown in Fig. 5a, with the inset of the photograph showing the three real devices. Fig. $5 \mathrm{~b}$ and c show the CV and GCD curves of the single, two and three fiber supercapacitors connected in series. Compared with a single device $(1 \mathrm{~V})$, the output of two and three devices connected in series exhibited a larger potential window of 2 and $3 \mathrm{~V}$, respectively. In the case of parallel connections (Fig. 5d and e), the output current (CV curves) and discharge time (GCD curves) of the three and two devices connected in parallel are increased by a factor of three and two compared with a single device at the same constant current of $1 \mathrm{~mA}$. Further, the CV and GCD curves of the integrated fiber supercapacitors (in series or parallel) exhibit 

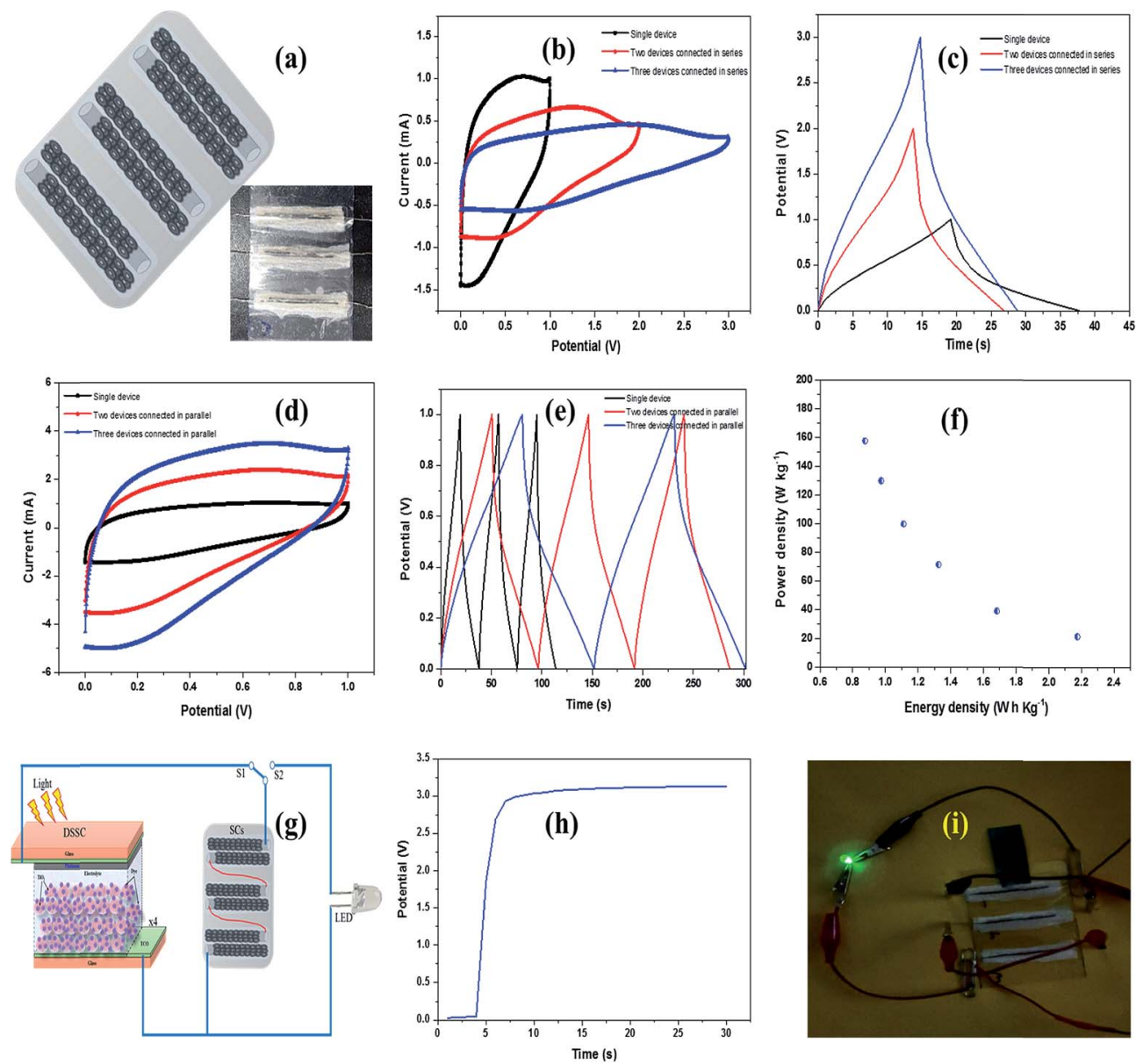

Fig. 5 (a) Schematic representation of the three fiber supercapacitors integrated into the PET substrate; the inset shows the digital photograph of assembled devices. CV curves of single, two and three fiber supercapacitor devices connected in (b) series and (d) parallel. (c) GCD curves of single, two and three fiber supercapacitors connected in (c) series and (e) parallel. (f) Energy density vs. power density of the fiber supercapacitor. Demonstration of the self-powered system: (g) schematic diagram of the integration of fiber supercapacitors with DSSCs and a LED. (h) Charging curve of the three fiber supercapacitors connected in series charged by four DSSCs in series. (i) The digital image of the green LED powered by three fiber supercapacitors in series charged using DSSCs.

ideal pseudocapacitive behavior. The calculated capacitances of the single, two and three parallel-wound devices were 18, 44, and $73 \mathrm{mF}$, respectively, which confirmed that the fabricated fiber supercapacitors roughly followed the basic rule of parallel connections. This result clearly indicated that the as-fabricated fiber supercapacitors could be connected in series or in parallel to drive various electronic devices as a variable operating voltage source.

Fig. $5 \mathrm{f}$ shows the energy density and power density of the fiber supercapacitors, which are two important parameters for evaluating the performance of energy storage devices. The calculated energy density of the symmetric supercapacitor is $2.18 \mathrm{~W} \mathrm{~h} \mathrm{~kg}^{-1}$ at a power density of $21.6 \mathrm{~W} \mathrm{~kg}^{-1}$, based on the total mass of the electroactive material. When the discharge current was increased to $1 \mathrm{~mA}$, the energy density still remained at $0.88 \mathrm{~W} \mathrm{~h} \mathrm{~kg}^{-1}$ at a power density of $157.5 \mathrm{~W} \mathrm{~kg}^{-1}$. The corresponding volumetric

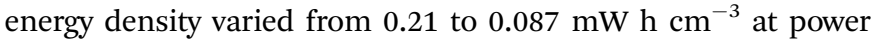
densities of 2.1 to $15.5 \mathrm{~mW} \mathrm{~cm}^{-3}$. These values are higher than or comparable to previously reported fiber-based solid state supercapacitors such as $\mathrm{ZnCo}_{2} \mathrm{O}_{4} / \mathrm{Ni}$-wire-SCs $\left(42 \mathrm{~mW} \mathrm{~h} \mathrm{~kg}{ }^{-1}\right.$ at $\left.0.50 \mathrm{~W} \mathrm{~kg}^{-1}\right),{ }^{16} \mathrm{CuCo}_{2} \mathrm{O}_{4} / \mathrm{Ni}$ wire-SCs $\left(0.77 \mathrm{~mW} \mathrm{~g}^{-1}\right.$ at $0.0961 \mathrm{~W}$ $\left.\mathrm{g}^{-1}\right),{ }^{15} \mathrm{NiCo}_{2} \mathrm{O}_{4} / \mathrm{Ni}$ wire-SCs $\left(1.44 \mathrm{~mW} \mathrm{~h} \mathrm{~cm}^{-3}\right.$ at $\left.17 \mathrm{~mW} \mathrm{~cm}^{-3}\right),{ }^{14}$

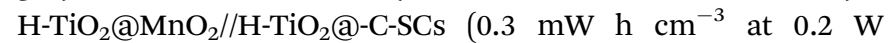
$\left.\mathrm{cm}^{-3}\right),{ }^{47} \mathrm{ZnO}$-doped $\mathrm{MnO}_{2}$ core-shell @C-SCs $\left(0.04 \mathrm{~mW} \mathrm{~h} \mathrm{~cm}{ }^{-3}\right.$ at $\left.2.44 \mathrm{~mW} \mathrm{~cm}^{-3}\right),{ }^{33} \mathrm{TiO}_{2} @ \mathrm{C}-\mathrm{SCs}\left(0.011 \mathrm{~mW} \mathrm{~h} \mathrm{~cm}{ }^{-3}\right.$ at $19 \mathrm{~mW}$ $\left.\mathrm{cm}^{-3}\right){ }^{34} \mathrm{MnO}_{2}$-coated ZnO NWs@C-SCs $\left(0.005 \mathrm{~mW} \mathrm{~h} \mathrm{~cm}{ }^{-3}\right){ }^{48}$ porous carbon-SCs $\left(311 \mathrm{~mW} \mathrm{~h} \mathrm{~kg}^{-1} \text { at } 58 \mathrm{~W} \mathrm{~kg}^{-1}\right)^{49}$ and carbon/ $\mathrm{MnO}_{2}$-SCs $\left(0.22 \mathrm{~mW} \mathrm{~h} \mathrm{~cm}^{-3}\right){ }^{18}$

To further demonstrate the proficiency and potential applications of our fabricated fiber supercapacitors, we assembled self-powered electronics based on DSSCs, fabricated fiber supercapacitors and LEDs. Fig. $5 \mathrm{~g}$ shows the schematic diagram of the self-powered device. The self-powered system consists of four series-connected home-made DSSCs (energy harvesting module), three series fiber supercapacitors (energy storage module), and a light emitting diode. Here, the DSSC, which harvests energy from sunlight, was used as an energy source to charge the supercapacitor. Then the stored energy was used to power the LED without disruption. The fabrication and photovoltaic characterization of the home-made DSSC is given in the 
Experimental section. The measured photovoltaic performance of the home-made DSSC under 1 sun irradiation is shown in Fig. S11. $\dagger$ The power conversion efficiency $(\eta)$ of the serially connected DSSCs is $6.96 \%$. Further, the open circuit voltage and short-circuit current of four serially wound DSSCs were $3.08 \mathrm{~V}$ and $3.94 \mathrm{~mA} \mathrm{~cm}^{-2}$, respectively. When the light was $\mathrm{ON}$, the series-wound DSSCs harvested solar energy and stored the energy in the serially connected fiber supercapacitors maintained at closed position S1 (switch). Fig. 5h shows the charging curve of the serially connected fiber supercapacitors. The supercapacitors could be charged to $3.2 \mathrm{~V}$ in around $60 \mathrm{~s}$. To show self-powered operation, a commercial LED was connected to the charged supercapacitors, and was illuminated by closing switch S2 and opening switch S1 (the solar energy source was in the OFF condition). Fig. 5i shows a green LED which remained lit for more than $5 \mathrm{~min}$. Further, the leakage current and selfdischarge of the series-wound fiber supercapacitors were measured as shown in Fig. S12a and b, $\dagger$ which are the most important parameters for determining the performance of the devices for real-world applications. This study demonstrated that fiber supercapacitors could store solar energy produced from DSSCs by integration with the DSSCs, which implies their enormous application potential in flexible, wearable and portable electronic devices.

Overall, the present results based on a 3D-porous nickel (3D-Ni) architecture on a Ni-wire substrate confirmed the short diffusion path length of ion/electron transport for easy access of electroactive sites in the $3 \mathrm{D}-\mathrm{NiCo}_{2} \mathrm{O}_{4} / \mathrm{Ni}$ nanostructure, which supports fast kinetics and excellent specific capacitance. The following research directions in the area of material synthesis and structural design for supercapacitor electrodes are proposed to further enhance the electrochemical performance of fiber based supercapacitors: (i) fabrication of a hybrid nanostructure based on carbon materials or 2D materials with pseudocapacitance behavior on a $3 \mathrm{D}$ porous current collector and further optimization of mass loading and interfacial interactions to utilize the synergistic effects between the individual components; (ii) construction of one dimensional nanostructures such as $1 \mathrm{D}$ nanowires and nanotubes on the 3D-porous-Ni wire current collector having optimal porosity and the required surface area for enhanced charge storage.

\section{Conclusion}

In summary, we successfully fabricated a flexible solid-state fiber supercapacitor by the planar integration of $3 \mathrm{D}-\mathrm{NiCo}_{2} \mathrm{O}_{4} /$ 3D-Ni electrodes. A facile and low cost approach was used to fabricate a 3D-networked metal current collector with electroactive materials. The fiber electrode delivered a high volumetric capacitance of $29.7 \mathrm{~F} \mathrm{~cm}^{-3}$ at $2.5 \mathrm{~mA}$ and it retained $28.9 \mathrm{~F} \mathrm{~cm}^{-3}$ at $20 \mathrm{~mA}$, which suggests an excellent rate capability in a three electrode system. The assembled flexible fiber supercapacitor showed enhanced capacitance, high efficiency, better cycling stability, and flexibility. The feasibility of the fabricated flexible fiber supercapacitor was demonstrated in a self-powered system by integrating them with DSSCs and LEDs. These promising results demonstrate that the flexible fiber supercapacitor has great potential in a wide range of applications, including flexible, wearable and portable electronic devices.

\section{Acknowledgements}

This work is supported by NRF with the contract no. NRF-2015R1A2A2A01005250 and 2015-M2B2A4030502 (National nuclear $\mathrm{R} \& \mathrm{D}$ program, MSIP) and the BK21 plus program.

\section{References}

1 Y. Hu, Y. Zhang, C. Xu, L. Lin, R. L. Snyder and Z. L. Wang, Nano Lett., 2011, 11, 2572-2577.

2 S. H. Lee, C. K. Jeong, G.-T. Hwang and K. J. Lee, Nano Energy, 2015, 14, 111-125.

3 A. Ramadoss, B. Saravanakumar, S. W. Lee, Y.-S. Kim, S. J. Kim and Z. L. Wang, ACS Nano, 2015, 9, 4337-4345.

4 T. Chen and L. Dai, J. Mater. Chem. A, 2014, 2, 10756-10775. 5 V. L. Pushparaj, M. M. Shaijumon, A. Kumar, S. Murugesan, L. Ci, R. Vajtai, R. J. Linhardt, O. Nalamasu and P. M. Ajayan, Proc. Natl. Acad. Sci. U. S. A., 2007, 104, 13574-13577.

6 X. Lu, M. Yu, G. Wang, Y. Tong and Y. Li, Energy Environ. Sci., 2014, 7, 2160-2181.

7 Y.-Z. Zhang, Y. Wang, T. Cheng, W.-Y. Lai, H. Pang and W. Huang, Chem. Soc. Rev., 2015, 44, 5181-5199.

8 D. P. Dubal, J. G. Kim, Y. Kim, R. Holze, C. D. Lokhande and W. B. Kim, Energy Technol., 2014, 2, 325-341.

9 M. Lee, S. K. Balasingam, H. Y. Jeong, W. G. Hong, H.-B.-R. Lee, B. H. Kim and Y. Jun, Sci. Rep., 2015, 5, 8151.

10 S. K. Balasingam, J. S. Lee and Y. Jun, Dalton Trans., 2015, 44, 15491-15498.

11 X. Cai, M. Peng, X. Yu, Y. Fu and D. Zou, J. Mater. Chem. C, 2014, 2, 1184-1200.

12 D. Yu, Q. Qian, L. Wei, W. Jiang, K. Goh, J. Wei, J. Zhang and Y. Chen, Chem. Soc. Rev., 2015, 44, 647-662.

13 K. Jost, G. Dion and Y. Gogotsi, J. Mater. Chem. A, 2014, 2, 10776-10787.

14 Q. Wang, X. Wang, J. Xu, X. Ouyang, X. Hou, D. Chen, R. Wang and G. Shen, Nano Energy, 2014, 8, 44-51.

15 S. Gu, Z. Lou, X. Ma and G. Shen, ChemElectroChem, 2015, 2, 1042-1047.

16 H. Wu, Z. Lou, H. Yang and G. Shen, Nanoscale, 2015, 7, 1921-1926.

17 B. Liu, D. Tan, X. Wang, D. Chen and G. Shen, Small, 2013, 9, 1998-2004.

18 X. Xiao, T. Li, P. Yang, Y. Gao, H. Jin, W. Ni, W. Zhan, X. Zhang, Y. Cao, J. Zhong, L. Gong, W.-C. Yen, W. Mai, J. Chen, K. Huo, Y.-L. Chueh, Z. L. Wang and J. Zhou, ACS Nano, 2012, 6, 9200-9206.

19 H. Sun, X. You, J. Deng, X. Chen, Z. Yang, J. Ren and H. Peng, Adv. Mater., 2014, 26, 2868-2873.

20 X. H. Xia, J. P. Tu, Y. Q. Zhang, Y. J. Mai, X. L. Wang, C. D. Gu and X. B. Zhao, J. Phys. Chem. C, 2011, 115, 22662-22668.

21 H. Jiang, Y. Guo, T. Wang, P.-L. Zhu, S. Yu, Y. Yu, X.-Z. Fu, R. Sun and C.-P. Wong, RSC Adv., 2015, 5, 12931-12936.

22 C. Yuan, J. Li, L. Hou, X. Zhang, L. Shen and X. W. Lou, Adv. Funct. Mater., 2012, 22, 4592-4597. 
23 V. H. Nguyen and J.-J. Shim, J. Power Sources, 2015, 273, 110117.

24 F. J. Heiligtag and M. Niederberger, Mater. Today, 2013, 16, 262-271.

25 J.-M. Li, C. Cai, L.-X. Song, J.-F. Li, Z. Zhang, M.-Z. Xue and Y.-G. Liu, Trans. Nonferrous Met. Soc. China, 2013, 23, 2300-2306.

26 V. Gupta, S. Gupta and N. Miura, J. Power Sources, 2010, 195, 3757-3760.

27 X. Y. Liu, Y. Q. Zhang, X. H. Xia, S. J. Shi, Y. Lu, X. L. Wang, C. D. Gu and J. P. Tu, J. Power Sources, 2013, 239, 157-163.

28 X. Wang, X. Han, M. Lim, N. Singh, C. L. Gan, M. Jan and P. S. Lee, J. Phys. Chem. C, 2012, 116, 12448-12454.

29 Z. Zhang, F. Xiao and S. Wang, J. Mater. Chem. A, 2015, 3, 11215-11223.

30 V. T. Le, H. Kim, A. Ghosh, J. Kim, J. Chang, Q. A. Vu, D. T. Pham, J.-H. Lee, S.-W. Kim and Y. H. Lee, ACS Nano, 2013, 7, 5940-5947.

31 X. Dong, Z. Guo, Y. Song, M. Hou, J. Wang, Y. Wang and Y. Xia, Adv. Funct. Mater., 2014, 24, 3405-3412.

32 H. Jin, L. Zhou, C. L. Mak, H. Huang, W. M. Tang and H. L. Wa Chan, J. Mater. Chem. A, 2015, 3, 15633-15641.

33 P. Yang, X. Xiao, Y. Li, Y. Ding, P. Qiang, X. Tan, W. Mai, Z. Lin, W. Wu, T. Li, H. Jin, P. Liu, J. Zhou, C. P. Wong and Z. L. Wang, ACS Nano, 2013, 7, 2617-2626.

34 H. Zheng, T. Zhai, M. Yu, S. Xie, C. Liang, W. Zhao, S. C. I. Wang, Z. Zhang and X. Lu, J. Mater. Chem. C, 2013, 1, 225-229.
35 X. Ding, Y. Zhao, C. Hu, Y. Hu, Z. Dong, N. Chen, Z. Zhang and L. Qu, J. Mater. Chem. A, 2014, 2, 12355-12360.

36 A. Ramadoss and S. J. Kim, Electrochim. Acta, 2014, 136, 105111.

37 J. B. Wu, Y. Lin, X. H. Xia, J. Y. Xu and Q. Y. Shi, Electrochim. Acta, 2011, 56, 7163-7170.

38 F. Cheng, Z. Tao, J. Liang and J. Chen, Chem. Mater., 2008, 20, 667-681.

39 C. Guan, J. Liu, C. Cheng, H. Li, X. Li, W. Zhou, H. Zhang and H. J. Fan, Energy Environ. Sci., 2011, 4, 4496-4499.

40 X. Xia, J. Tu, Y. Zhang, X. Wang, C. Gu, X.-b. Zhao and H. J. Fan, ACS Nano, 2012, 6, 5531-5538.

41 Y. Li, Y. Zhang, Y. Li, Z. Wang, H. Fu, X. Zhang, Y. Chen, H. Zhang and X. Li, Electrochim. Acta, 2014, 145, 177-184.

42 M.-J. Deng, C.-Z. Song, C.-C. Wang, Y.-C. Tseng, J.-M. Chen and K.-T. Lu, ACS Appl. Mater. Interfaces, 2015, 7, 9147-9156.

43 J. Yan, Z. Fan, T. Wei, W. Qian, M. Zhang and F. Wei, Carbon, 2010, 48, 3825-3833.

44 A. Ramadoss and S. J. Kim, Carbon, 2013, 63, 434-445.

45 Y. Xu, Z. Lin, X. Huang, Y. Liu, Y. Huang and X. Duan, ACS Nano, 2013, 7, 4042-4049.

46 M. Li, Z. Tang, M. Leng and J. Xue, Adv. Funct. Mater., 2014, 24, 7495-7502.

47 X. Lu, M. Yu, G. Wang, T. Zhai, S. Xie, Y. Ling, Y. Tong and Y. Li, Adv. Mater., 2013, 25, 267-272.

48 J. Bae, M. K. Song, Y. J. Park, J. M. Kim, M. Liu and Z. L. Wang, Angew. Chem., Int. Ed., 2011, 50, 1683-1687.

49 S. T. Senthilkumar and R. K. Selvan, ChemElectroChem, 2015, 2, 1111-1116. 